like crying for the Moon, we have some twinges of regret that the subject matter is restricted to the geographic boundaries of the Commonwealth. So excellent is the treatment that we feel it could very profitably have been widened in scope to include, if not the world, at least the United States whose inclusion would not have raised any language difficulties. It is pertinent to note that this gap is to some extent filled by a fairly recent publication (Important Forest Insects and Diseases of Mutual Concern to Canada, the United States and Mexico. Edited by A. G. Davidson and R. M. Prentice, Ottawa, 1967). This publication deals, however, only with a very limited number of insect and fungal pathogens and with some parasitic higher plants, so that it is not really comparable with Browne's all-embracing review.

Myles Crooke J. S. MURRAY

\section{LESSON IN NON-SPECIALIZATION}

\section{Nerve Cells and Insect Behavior}

By Kenneth D. Roeder. Revised edition. (Harvard Books in Biology, No. 4.) Pp. xiii +238 . (Harvard University Press: Cambridge, Mass.; Oxford University Press: London, 1967.) 52s, $6 d$.

Professor Roeder himself describes the objective of this book as "to record in readable form a rather personal exploration of some of the nervous mechanisms responsible for insect behavior". It is difficult to phrase a more apt description. A subsequent, almost apologetic statement that it is therefore "one-sided" is not so justified, for a less one-sided investigator is hard to imagine.

The author is very much concerned with techniques. At the outset he analyses the established methods for investigating behaviour and nervous mechanisms. $\mathrm{He}$ emphasizes the virtues and limitations of each, with special attention to the different ways in which observation influences the responses of the subject. But whereas most workers are drawn to one approach by personal inclination, Roeder himself remains scientifically free, rejecting any title ending with "-ologist" and refusing to let technique select the problem to be studied.

His story centres around the detection and avoidance of predatory bats by nocturnal moths, and two large chapters on this phenomenon have been added to the otherwise little changed text of the 1963 edition. Although this subject is fascinating in its own right, it is especially amenable to analysis because the entire sensory input ("neural parsimony" with only two neurons from each ear) can be completely defined and because the response is largely mediated by the single pterothoracic ganglion. But this does not make the study simple and a wide variety of techniques is used in turn to unravel it.

Field observation establishes the complexity and variability of the response, instrumental experiments determine its sensitivity and latency, while neurophysiological recording with microelectrodes gives the sensory code, the range of possible information received by the ganglion and the responses of some of the internuncial neurons. The beauty of the work is not only in the skill with which it is performed, or even in the ingenious directness of the methods, but in the enviable clarity with which pertinent questions are continually asked and the problems redefined. The author turns from screened cage to the field and back again, never in a "blind alley", always seeing neurons as parts of "a living creature ... going about its natural business".

If even this should seem one-sided, the story is put into a broad context by comparison with other nervous mechan. isms in grasshoppers, cockroaches, praying mantis and vertebrates. The literary style is admirably clear, light and often humorous ... "the motor neuron (of vertebrate spinal cord) is a position analogous to that of an ad- ministrator. . . . It is tempting to liken the intimate anticonvulsive feedback provided by the Renshaw cell to the administrator's wife". In the end the author "withdraws" still further and achieves a curiously effective insight into some aspects of the individual life and affairs of an insect. The result is not a textbook of insect neurophysiology, although ideal reading for undergraduates, not a mere source of facts but a stimulus to enthusiasm for research and for the fascinating problems posed by living animals. One is left hoping that further editions will appear regularly, keeping the reader up to date with future progress. J. D. PYE

\section{BLOOD FLOW}

Blood Flow through Organs and Tissues

Edited by William H. Bain and William Harper. (Proceedings of an International Conference, Glasgow, March 1967.) Pp. $\mathrm{xx}+$ 515. (Livingstone: Edinburgh and London, 1968.) 848.

THIs book represents the proceedings of an international conference on blood flow held in Glasgow in March 1967. The first papers are about the measurement of blood flow in vessels and further sections are devoted to the measurement of blood flow in the heart and lungs, brain, muscle and skin and other organs. Each paper is followed by a detailed report of the subsequent discussion. This is very useful in revealing the reservations that authors may have about their techniques, which are not always evident in their papers.

As much of the interest in this book is the problem of applying to man existing methods for measuring blood flow, the first section will be of great interest to surgeons and clinical physiologists. There are a number of papers dealing with indicator dilution techniques, using dye or thermal dilution, together with a critical discussion of their limitations. It seems that there is still a large area of disagreement over the conditions for mixing and the extent of the error in measuring flow. The use of strain gauge and electrical impedance plethysmography is described, and for those with more expensive tastes the advantages and problems of electromagnetic flowmeters. The description of two velocity probes built into the tips of very small catheters seems to offer a technique of great promise.

The section on the heart and lungs contains full and clear descriptions by a number of authors of the techniques of measuring cardiac output by precordial counting, after the injection of radioactive iodinated serum albumin or $\mathrm{Xe}^{133}$. Brain blood flow is dealt with in two comprehensive sections. The first describes attempts to measure flow in different parts of the brain by clearance of hydrogen gas, radioactive inert gases and by heat clearance, which has become fashionable again although the problems of calibration and linearity remain difficult. The validity of the clearance of inert gases is examined in great detail both in theory and in model systems, and the limitations of the techniques are clearly defined. The second section on brain blood flow describes the regulation of cerebral blood flow in animals, the main problem being the mechanism of cerebral autoregulation. There are also some interesting papers on cerebral blood flow in man in various diseases.

The rest of the conference was concerned with a few papers on skin blood flow by clearance methods, the measurement of muscle blood flow, particularly in exercise, pancreatic blood flow, gastric mucosal flow and renal autoregulation. An account of renal blood flow after transplantation and rejection is of special interest.

The book is easy to read, very well illustrated and contains a large amount of information in its 515 pages. It will be extremely useful for those interested in blood flow and is worth careful study.
D. Mendel 